\title{
The Impact of COVID-19 on the Mental Wellbeing of Youth Around the World: A Statistical Analysis
}

Victoria McDermott ${ }^{1}$, Sai Mattapalli ${ }^{2}$, Alondra Rodriguez-Solis ${ }^{3}$, Ana Anariba ${ }^{4}$, Cara Eng Chang $^{5}$, Aarush Santoshi ${ }^{6}$, Sofia Penttila ${ }^{7}$, Stefan Alek Salaices ${ }^{8}$, Matthew Kim ${ }^{9}$

Jones College Preparatory School ${ }^{1}$, Thomas Jefferson High School for Science and Technology ${ }^{2}$, University of California, Berkeley ${ }^{3}$, DelCampo International School ${ }^{4}$, Academy of the Holy Angels ${ }^{5}$, Bergen County Academies ${ }^{6}$, Notre Dame High School ${ }^{7}$, Colleyville Heritage High School $^{8}$, Oakton High School ${ }^{9}$ 


\begin{abstract}
Background: This study examines previous research and open-source data to analyze COVID-19's impact on youth mental health. It evaluates how certain factors, such as geographical location, race, and sexual orientation, may increase children's likelihood of developing a mental disorder during the pandemic.
\end{abstract}

Methods: We statistically analyzed the open-sourced COVID-19 and its Impact on Students data set. We filtered the responses so that our results included participants who were all under 18. Google sheets were used to plot the survey data and analyze correlations.

Results: Students ages 7-17 spent an average of $0.82 \mathrm{~h} /$ day [95\% CI 0.76-0.89] exercising, $7.91 \mathrm{~h} /$ day [95\% CI 7.77-8.11] sleeping, and $1.68 \mathrm{~h} /$ day [95\% CI 1.52 - 1.85] using social media. Time spent in online classes for students ages 7-17 was significantly higher compared to other age groups (3.69 h/day). $31.5 \%$ of students in this group negatively reviewed their quality of e-learning $(2.4 \%$ poor and $29.1 \%$ very poor). Additionally, $51.4 \%$ of responders were not satisfied with their use of time. Further testing revealed emotional and cognitive health declined sharply in participants dissatisfied with their use of time. To cope with the pandemic, $26 \%$ of the surveyed students listened to music, $21 \%$ played online games, 9\% read, $9 \%$ used social media, $8 \%$ slept, and $27 \%$ used other methods.

Conclusions: After a conclusive review of previous research, we can confirm that COVID-19 harmed children's emotional and cognitive health to a great extent. Although the seriousness of psychological symptoms felt by young people varied from region to region, COVID-19 led to an overall decline in mental health in groups ages 10-18. Hopefully, health officials will recognize the mental health crisis at hand and will devise new means to support children's psychological health. 


\section{Introduction}

Last year, COVID-19, a respiratory disease caused by the virus SARS-CoV-2, managed to infect more than 200 million humans, result in almost 5 million deaths, and establish itself as a prevailing matter in all facets of life (Worldometer, Coronavirus cases). While the medical details of COVID-19 have seen extensive research, relatively less attention has been paid to its mental health effects, especially in the context of children and adolescents. Our aim in this report is to discuss and analyze the various results of previous studies in this field and conduct our own analyses to bring forth new conclusions. The creation of this report was overseen by the World Health Organization's EPI-WIN Team.

\section{Literature Review}

Despite an apparent slowdown in cases and deaths since late August 2021, the effects of the pandemic reach far beyond the loss of human life. Mental health-related claims for adolescents ages 13-18 increased sharply between 2019 and 2020, while 22\% of parents with children ages 5-12 reported worsened mental or emotional health (Panchal et al. 2020). Reports by the World Health Organization (WHO) attribute these drastic trends to mandatory quarantine disrupting individual routines, resulting in a heightened risk of experiencing loneliness, depression, and self-harm (Mental Health and COVID-19). Particularly in children, who were often separated from primary caregivers who worked in densely-populated environments with a high risk of exposure to COVID-19, psychiatric disorders were found to have an increased risk of being present due to separation pushing children into a state of panic (Liu et al. 2020).

Furthermore, children may respond to stress in varying ways: commonly through withdrawing from communal activities and growing agitated. To avoid these responses, children, especially between the ages of 1-3, must avoid separation when possible (World Health Organization, 2020). Children develop vulnerable coping mechanisms and responses to the added stress when placed in a pandemic that deprived them of their emotional necessities. Indeed, $30 \%$ of quarantined children were subsequently diagnosed with post-traumatic stress disorder (Liu et al. 2020). An October 2021 UNICEF report found that more than 1 in 7 adolescents aged 10-19 were living with a mental health disorder (UNICEF, 2021). The effects of parental separation also have prolonged adverse effects on mental health. Depending on the age of initial separation, children are found to have experienced an amplified risk of developing mood disorders and suicide during adulthood (Liu et al. 2020). In adolescents, negative thoughts surrounding the disruption of routines drive many to use drugs and alcohol (Panchal et al. 2020). 
All of this is compounded by pre-pandemic apexes of diagnosed mental health conditions, suicide, and substance abuse (Panchal et al. 2020). The early development of such conditions increases the likelihood of persisting into adulthood, consequently increasing the risk of death (Panchal et al. 2020). However, even when governments implement measures to relieve the pandemic's psychological burden on children, they are unlikely to suffice, as most localized support focuses only on meeting basic daily needs (Liu et al. 2020). Before the pandemic, children with mental health needs were barred from receiving care due to the expensive cost of treatment, lack of providers, and limited insurance coverage. In 2018, the WHO found that 0.36 paid mental health workers were available per 100,000 people in India, a situation only exacerbated by the pandemic (World Health Organization, 2018). Indeed, although medical innovations have afforded the international community a slight glimmer of hope for an end to COVID-19, its lasting mental health impacts, both on young children and adolescents, is a reminder that the fight is not yet finished.

COVID-19 harmed children's emotional and cognitive health to an extreme extent. The sudden disruption of everyday life caused by stay-at-home orders, school closures, and other quarantine restrictions forced students to quickly adapt to online, isolated environments (Choukér \& Stahn 2020). This abrupt change, followed by income insecurity and fear for loved ones, heavily impacted youth mental states worldwide (Singh et al. 2020). While the severity of psychological symptoms varied between countries and groups, the following research concludes that COVID-19 led to a decline in emotional and cognitive health in groups ages 10-18.

December 2019 marked the appearance of COVID-19 in Wuhan, China (BS \& Nambiar, 2020). Getting an insight into the potential discrepancies of mental health outcomes for adolescent mental health between those residing in Wuhan in comparison to other Chinese urban areas is important in painting the picture of risk factors within these areas. Data from 7,866 adolescents was collected from the cities of Wuhan, Beijing, and Hangzhou. Participants completed multiple questionnaires, including the Patient Health Questionnaire-9 (PHQ-9), the Generalized Anxiety Disorder-7(GAD-7), and the Short Egna Minnen Beträffande Uppfostran to assess participants' anxiety and depression levels. After taking into account factors such as gender, siblings, infected relatives, and virtual learning experiences, a sample t-test was used to analyze differences in the questionnaire data. With the use of a Chi-square test, it was found that there was a significant increase in anxiety in respondents from Wuhan when compared with Beijing and Hangzhou. 
As the virus spread, COVID-19 increasingly harmed Chinese citizens' emotional health. A web-based cross-sectional survey found that $33 \%$ of young adults living in China had generalized anxiety disorders and 18\% suffered from depressive illnesses (Huang Y, Ning Z. Med Rxiv 2020). Additional studies revealed more than $50 \%$ of China reported moderate to severe psychological symptoms, and around $20 \%$ had severe stress impairments from the pandemic (Wang et al. 2020). Researchers mention a decline in mental health last year is likely directly linked to the changes coronavirus ensued, such as strict social restrictions, economic decline, and health concerns. As predicted, the pandemic's implications decreased mental health in China (Lima CKT, et al. 2020).

Adolescents living in low and middle-income countries were more prone to mental illnesses pre-pandemic, but the stress of the pandemic exacerbated existing risk factors, such as poor health, education, violence, and poverty. Worldwide there have been reports of heightened stress and anxiety in countries like Lebanon, Ethiopia, and Côte d'Ivoire. Research on these countries was conducted via phone interviews with 119 adolescents aged 15-19 in Ethiopia, 349 adolescents aged 10 to 19 in Côte d'Ivoire, and 100 adolescents ages 15-19 from Lebanon. Researchers discovered higher levels of health anxiety in Lebanon, where care is hard to access due to high costs. Family members with underlying health conditions expressed the highest levels of anxiety in Lebanon. Some participants lived in large camps and mentioned social distancing was difficult in their environment. Those who lived in camps had increased amounts of stress. As a result of limited resources and strenuous circumstances made worse due to the COVID-19 pandemic, this group of adolescents has experienced many barriers that changed their external environment that in turn affected their mental and physical wellbeing.

With the COVID-19 virus in full force, many countries enforced school closures, Turkey included. To understand how these closures affected Turkish adolescents, a 745 participant study used self-reported surveys from students aged 12 to 18 in 13 different schools. The collected data included a Sociodemographic form, State-Trait anxiety scale, and the University of California, Los Angeles' loneliness survey. $11.3 \%$ of the participants had previous psychiatric referrals, and $18.4 \%$ had a family member who contracted COVID-19. 56.4\% reported no change in anxiety levels. $58.1 \%$ of participants reported an increase in individual health concerns during quarantine.

During Switzerland's strict lockdown, a study analyzed the mental health of children ages 12-17 and their parents during the pandemic. The study examined symptoms of ADHD, ODD, depression, anxiety, and internet usage using a combination of scales in an online survey. The purpose of the study was to provide further research on child psychiatry (Wang et al. 2020; 10). The majority of psychiatry research during the 
pandemic was focused on adults and Asian countries, especially China. It is also important to analyze the effects of the lockdown on a country that is considered to be highly developed to extend potential solutions and methods to other countries. For the focus of this study, only the research concerning children and adolescents will be included.

Recruited via email, 1,146 children and adolescents with an average age of 14.5 (standard deviation of 1.7) completed a short 20-minute survey. The Corona Health App Questions were used for analyzing ADHD, ODD, depression, and anxiety (Cordes et al. 2021). In addition to the Corona Health App Questions, the Kiddie Schedule for Affective Disorders and Schizophrenia, Spence Children's Anxiety Scale for Children, a compulsive internet use scale, and the Responses to Stress Questionnaire were used to analyze additional psychological symptoms and problematic internet usage in respondents. More than a third of participants screened positive for one mental health symptom. ADHD was the most common disorder (22.7\% of girls, $23.3 \%$ of boys), followed by ODD symptoms (18.2\% of girls, $11.2 \%$ of boys), anxiety (13.6\% of girls, $12.5 \%$ of boys), and depression ( $9.7 \%$ of girls, $4.6 \%$ of boys). ADHD and ODD rates were higher than expected. This finding is consistent with other research during the pandemic.

ODD is traditionally higher in boys, but this study reported especially high ODD rates in girls. On the same note, girls typically have lower rates of ADHD, but ADHD rates in this study were nearly identical across genders (Willcutt, 2013; Drechsler et al. 2020; Thapar, Cooper, 2016; Demmer et al. 2017, Canino et al. 2010). Depression and anxiety levels were lower than expected in this study. One Italian study found a similar increase in ADHD symptoms in children during the pandemic, but not for general psychological adjustments (Cusinato et al. 2020). A German study also found similar ADHD levels in children (Drechsler et al. 2020) This presents an interesting idea that the first wave of the pandemic may have manifested itself more in ADHD and ODD symptoms than in depression and anxiety, which is possibly an effect of online school. The fact that most school curriculums weren't designed with the intention of teaching virtually has led many students to feel bored and overwhelmed. But, this doesn't explain why depression and anxiety levels remained steady. Surprisingly, during the pandemic, young adults exhibited depressive symptoms followed by anxiety and ADHD-related symptoms, while children exhibited the opposite: more anxiety and ADHD with less depressive symptoms. This may be because ODD and ADHD are more popular in children (American Psychiatric Association, Mental Disorders, 2013; Beauchaine \& Hinshaw, 2015) and begin to decline moving into adulthood (Willoughby, 2003; Atherton et al. 2018; Nock et al, 2007). 
In general, stress surrounding social activities was much more common in children compared to adults. Stress as a result of difficulties with online school work was the highest among children (16.5\% of boys, $18.7 \%$ of girls). Stress levels were similar across genders but were slightly higher in girls.

In the Swiss internet survey, more than $40 \%$ of males and $35 \%$ of females used the internet for more than 4 hours per day. The median time children, adolescents, and young adults spent online each day was 240 minutes. Around a third of children and adolescents met the criteria for problematic internet usage. Problematic internet use was more frequent in boys. $6 \%$ of girls and $3.3 \%$ of boys reported sleeping problems. The most commonly reported internet usage issues were "difficult to stop" (loss of control was mentioned in $24.4 \%$ of surveyed girls), and "looking forward to the next internet session (preoccupation was found in $29 \%$ of surveyed boys). Sometimes participants felt compelled to use the internet when they were feeling down (18.6\% in girls, $9.2 \%$ in boys). The study found that problematic internet use was associated with an increase in mental health issues.

In its totality, the study has shown the concerning trends of the mental health effects on our youth. Mental health during childhood is especially relevant considering it has drastic long-term effects (Monroe \& Harkness, 2005; McLaughlin et al. 2010; Bandoli et al. 2017). It's important to guide children to maintain social contact with immediate family members during the pandemic to progress social development. Although this study mentioned one-third of participants tested positive for a mental issue, it's important to note a survey indicator is not a complete diagnosis.

Many articles mention the mental consequences of COVID-19, but an increase in substance abuse among children due to heightened stress, anxiety, and depression levels is often excluded in researchers' analyses (Fegert et al. 2020; Galea et al. 2020). In a 2020 study, researchers studied relationships between Canadian adolescents' mental health and substance use during the pandemic. The study asked 809 Canadian citizens aged 12-18 (An average age of 15.67, SD of 1.37) to self-report mental health symptoms and what substances they used to cope (if any). The scales used in the assessment were combinations of the Ontario Child Health Study Scales, the Children's Revised Impact of Event Scale, the COVID-19 Stress Scale, and a Drug History Questionnaire. The Ontario Child Health Study Scales is a 52 question measure of emotional and behavioral problems across multiple scales, examining many disorders such as CD, ODD, ADHD, Depression, Anxiety, Separation Anxiety, and Social Phobias. T-scores for this study were calculated using previously established norms (Duncan et al. 2019). The Children's Revised Impact of Event Scale is a measure for determining susceptibility to PTSD. The total range was 0-65, with a clinical cut-off of 30 (Perrin et al. 2005). The COVID-19 Stress Scale is a measure 
of the impact of COVID-19 stressors on mental health and was grouped into a subscale based on health concerns (Findlay et al. 2020). The Drug History Questionnaire asked participants if they used recreational drugs, and if so, how often (Sobell et al. 1995). 67\% of participants reported at least one mental symptom of clinical concern; $16.4 \%$ of the group had declared one symptom, $15 \%$ declared two, $14.7 \%$ declared three, and $21.3 \%$ declared four or more. Examining the mental symptoms across genders revealed that female participants self-reported higher levels of depression, anxiety, social phobia, and PTSD compared with male participants. Additionally, transgender or nonbinary respondents (TNBI) experienced more symptoms of ADHD, depression, anxiety, social phobia, and PTSD compared with surveyed boys and girls. Girls and TNBI respondents reported higher levels of separation anxiety and ODD. There was no significant difference across genders for conduct disorder. The Drug History Questionnaire revealed that the most commonly used substances among participants were alcohol (42.3\%), nicotine (16.5\%), and cannabis (20.7\%). Roughly one in five people (19.7\%) reportedly engaged in regular (defined as once a week or more) use of at least one substance. Substance use did not differ when analyzed across gender $(\mathrm{p}>.05)$. Given that COVID-19 isolating restrictions are long-term, its mental health effects will likely become increasingly clear and concerning as the pandemic progresses. These observations highlight a clear trend in the pandemic's negative influence on emotional health and call for additional and more accessible mental health programs, especially for girls and non-binary teenagers.

To address the varying demographics found within United States' youth, and how potential rises in child abuse impacted US children's mental health, multiple studies analyzed the mental consequences of COVID-19 in adolescents, small children, LGBTQ youth, and BIPOC children living in the United States (Panchal et al. 2021). Researchers discovered the isolated and volatile environments developed by income insecurity, stay-at-home orders, and school closures served as risks to children's mental health and suggested a rise in child abuse (Panchal et al. 2021) 25\% of American high school students reported psychological symptoms after quarantine restrictions were placed. Only one-third of students stated they were able to cope with their stress during the pandemic. Additionally, more than $20 \%$ of parents with children ages 5-12 reported their children experienced negative mental health symptoms at this time. A survey collected responses from groups ages 13-17 and members of the LGBTQ community, from which the majority of participants reported symptoms of anxiety (73\%), depression (67\%), and suicidal thoughts (48\%) during the pandemic (Panchal et al. 2021). Data for colored children's emotional and cognitive health during the pandemic was limited, but older research suggests BIPOC children had higher rates of mental illnesses and were less likely to access treatment, regardless of the rates at which they experience psychological problems (Panchal et al. 2021). Pre-pandemic, a large number of children with mental 
health needs were not receiving treatment, and as the pandemic continued, the number of children not accessing care worsened. Data shows that there have been large declines in pediatric mental health care utilization since the pandemic began. However, private insurance data points out that while all health care claims for children ages 13-18 were low in 2020, mental health-related claims for this age increased significantly (FAIR 2021). This decline can be attributed to nationwide educational facility closures since pre-pandemic, students could access emotional resources via schools. The many social restrictions in place created lonely, depressive spaces for children. Young children are especially subject to separation anxiety because of separation from caretakers and parents from quarantine restrictions. Parents' health has also declined during the pandemic due to financial and social hardships. Poor parental health likely leads to decreases in children's mental health and an increase in child abuse (Panchal et al. 2021). Although data is unclear if child abuse rates have risen during the pandemic, media reports suggest it has increased. Child abuse results in serious lifelong emotional and psychological consequences and increases the likelihood of mental illness and substance misuse later in life. As schools closed due to student health concerns, reports of child abuse have dropped and abuse-related emergency department (ED) visits have decreased. However, the seriousness of injuries among abused children has increased, suggesting that only severe cases of child abuse are noticed. Teachers and school staff often identify and report child abuse, and it is predicted that school closures are allowing for many cases to remain hidden. While the previously mentioned studies are unsure of the severity of mental health declines in US children due to limited data, most assume that no matter the demographic, American children's mental health declined during the pandemic.

Along with social restrictions, COVID-19 led to an increase in racial discrimination towards Asians, especially in the United States. Similar to the previously mentioned studies, discriminatory comments and behavior created similar psychological symptoms in Asian Americans. Data collected from the University of Southern California's Center for Economic and Social Research Understanding Coronavirus in America survey compared the psychological states of Asian Americans, Asian immigrants, and white Americans during the pandemic (Wu et al. 2021). The survey revealed Asian Americans and Asian immigrants living in the United States experienced larger amounts of mental disorders compared to white Americans. This study also highlights differences between the mental health and discrimination rates of Asian Americans and Asian immigrants during the pandemic. Pre-pandemic, Asian Americans reported fewer mental health illnesses than white Americans (Asnaani et al. 2010). Researchers suggest the rise in psychological disorders among Asian Americans and immigrants coincides with the increasing amount of attacks against people of Asian descent. As COVID-19 cases rose, Asians were increasingly targeted and blamed for the virus. Last year, Anti-Asian hate crimes surged by nearly $70 \%$ in the United States 
(Mangan 2021). A considerable amount of Asian Americans mentioned they were verbally attacked or felt unsafe because of their race. $31 \%$ of US adult Asians received slurs or racist comments, and 26\% said they feared someone would physically harm them (Wu et al. 2021). After the first outbreak, more than $40 \%$ of Americans reported they were discriminative to Asians at least once in March 2020 (Dhanani \& Franz 2020). Past studies heavily suggest racism harms a race's mental and physical health, so researchers expected an increase in psychological disorders/symptoms within Asian Americans (Ong et al. 2017). Previous research also showed that racial discrimination is associated with greater psychological problems, anxiety, depression, and suicidal thoughts within a race (Gee et al. 2009). To analyze correlations between Asian American discrimination and mental health, the University of California collected responses from 8,500 individuals ages 18 and older. Respondents were members of the Understanding America Study, an online internet panel. Although the collected data does not directly represent Asian American children's psychological states and COVID-19 experiences, previous studies revealed parents' racial experiences impacted their children's mental health (Cheah et al. 2020). Therefore, the Understanding Coronavirus in America results may offer insight into both adult and youth emotional health at this time. Each surveyed group was given a score for depression, anxiety, and discrimination according to their responses. A higher score conveys a higher number of group members who experienced the aforementioned qualities. White Americans had a depression and anxiety score of 1.98 [95\% CI, 1.95-2.00], Asian Americans had a score of 2.96 [95\% CI, 2.82-3.11], and Asian immigrants' score was 2.16 [95\% CI, 2.05-2.28]. The notable difference between the depression and anxiety scores of Asians and white Americans suggests that the impact COVID-19 had on mental health was felt much more greatly by Asians (Liu et al. 2020). Asian Americans had an average discrimination score of 0.75 [95\% CI, 0.68-0.82], Asian immigrants had a mean score of 0.68 [95\% CI, 0.62-0.74], while whites had a mean score of 0.31 [95\% CI, 0.30-0.32]. It is reasonable to conclude that the extreme differences across groups directly relate to the surge in Asian discrimination from the pandemic.

As the pandemic evolves, it has become clear that its effects have and will continue to be unequal. Underdeveloped countries, such as those in Latin America, have been more severely impacted by the pandemic than developed countries; data has shown that surviving through the pandemic heavily relies on economic wealth. The pandemic has increased multiple types of inequality, and it has proven inequality to be multidimensional: affecting economic well-being, physical, and mental health.1 During youth, household and parental dynamics, individual educational experience, peer behavior, role models, social capital, access to information, among other things, have proven essential to individual development, as concluded in Oxford University's Young Lives longitudinal study. Given the fact that Latin American countries have a fragile status of education policies, parenting practices are strongly correlated with 
socioeconomic status, and poorer communities are less likely to possess workability, it is easy to conclude that the Latin American youth are among the group of individuals that will be the most affected by the pandemic since their countries are characterized by great levels of inequality. 2 Due to the importance of childhood development in predicting long-term outcomes, we can conclude that the youth in Latin America are among the group that will be most affected by the pandemic, to the point of affecting their future generations too. The following effects that the pandemic has had on the Latin American youth focuses on children between the ages of 5 to 18. A study conducted by Acevedo in 2020 showed that the majority of children lost more than one quarter of their school year, which affected a wide range of areas of the students' lives, including self-esteem; it also and enabled a situation where there is a greater likelihood of domestic violence and regression on gender parity. The previously mentioned study also pointed out that students from poorer families face a significantly greater decline in learning time than developed countries. A recent UNICEF report stated that 97\% of Latin American students experienced a disruption in their education; they have lost approximately 174 days of school, four times as much as the rest of the world, and due to the privatization of education in Latin America, it is predicted that only one-third of the students will have access to quality education during the pandemic. 4 Schools attended by the poorest students were the least prepared for this situation, and their family environments were not deal due to the relationship between parenting and socioeconomic status. These students, from disadvantaged backgrounds, are the least prepared to manage this new situation; consequently, they are left with a stressful situation and no proper guidance on how to deal with it, and as a result, their mental health is likely to deteriorate and exacerbate pre-existing inequalities, since this situation can lead to complete withdrawal from formal education. 3 Aside from education, the lack of policies that have been implemented that aim at containing the negative effects of the pandemic, further worsen the situation that the youth is facing. For example, conditional cash transfer programs (CCT) have played an important role in Latin American countries, such as "Bolsa Familia" in Brazil and "Familias en Acción" in Colombia; however, several countries have cut back these helpful programs, such as Mexico. These programs have played a fundamental role in serving the underprivileged youth in the pandemic; for example, "Familias en Acción" in Colombia incorporate important community life aspects, aside from the economic relief. By doing so, the program can give the youth role models, who are fundamental for their proper development and strengthen their ability to cope with the new, stressful situation they are facing. However, several of these programs have stopped operating during the pandemic in many Latin American countries, in addition, parent guidance programs have also ceased to exist. Aside from the fact that crowded environments and limited resources, the living conditions of the majority of the Latin American youth, generate mental health problems and have negative impacts on child development; the lack of appropriate parenting is an issue that should be addressed. The COVID-19 crisis has parental behavior 
changes, and in Latin America, those changes are usually not discussed. Women have suffered more, in terms of employment, than men, which prevents progress in gender parity; this reality can lead the youth to have a negative perception of themselves. Adolescents are usually given temporary responsibilities during the pandemic, which aside from potentially leading to permanent withdrawal from education, places pressure on the adolescents, which leads to great levels of stress, insomnia, and other mental health problems. The pandemic has increased violence at home in Latin America, and this can lead to a myriad of mental health problems for the youth, such as anxiety and depression. 5 Overall, these problems that the Latin American youth are facing are usually overlooked; however, it is important to address them since youth find themselves in an environment that is characterized by great inequality, which is the main enabling factor of many situations that lead to mental health problems.

UNICEF conducted a rapid assessment, around September 2020, to 8,444 adolescents and young people between the ages of 13 and 29 in nine countries and territories in Latin America and the Caribbean. $27 \%$ of individuals reported feeling anxiety and $15 \%$ depression within the last 7 days, for $30 \%$ of these individuals, economical problems are the reason for their mental health status. Their daily lives have also been affected, as $46 \%$ stated having less motivation to do enjoyable and $36 \%$ feel less motivated to do regular chores. An important thing to note is that $43 \%$ of women feel pessimistic about their future, while $31 \%$ of men feel this way.

Communities throughout Latin and South America were already struggling to meet mental health and psychological resources demands within adolescent populations, before being hit hard by the COVID-19 pandemic. The trend of minimal mental health and cognitive resources within Latin American countries is particularly prevalent in Guatemala, a nation that experienced an alarming surge in COVID-19 infections and deaths compared to neighboring nations. Pre-pandemic, almost half of Guatemalan children were suffering from chronic malnutrition, with even higher rates in Indigenous communities. Despite experiencing moderate economic growth in years prior to the pandemic, mass poverty levels remained relatively stagnant and have only worsened from COVID-19. A study conducted by the International Journal of Social Psychiatry within the region utilizing phone interviews between researchers and residents across multiple districts in Guatemala, where less than $1 \%$ of the country's general health budget is spent on psychological care, found that teens experienced high levels of anxiety and stress as a product of being isolated from peers during the COVID-19 pandemic (Alonzo, Popescu, \& Zubaroglu-Ioannides 2021). The study utilized interviews, sociodemographic and medial information, chi-square and t-tests, and binary logic to access the mental states of 295 individuals. 
The study concludes that individuals residing in communities with pre-existing poverty, high crime rates, food insecurity, lack of resources, and normalized violence were hit hardest by the pandemic. In many cases, the pandemic exposed underlying vulnerabilities within many communities and prolonged the impacts these vulnerabilities will have on the long-term well-being of adolescents residing within them. The study finds that $64 \%$ of the sample reported symptoms of anxiety, $47 \%$ of stress, $25 \%$ an increase in intensity of pre-existing mental health conditions, $19 \%$ depression, $18 \%$ burnout, and $5 \%$ concerns about safety at their homes (Alonzo, Popescu, \& Zubaroglu-Ioannides 2021).

The study discovered an exponential increase in teen pregnancy rates. Determining that teen pregnancies can likely be attributed to the closing of schools, a lack of child care support services, and a further increase in women's responsibilities to care for ill family members. Without the proper resources and support systems, young Guatemalan girls were left in a particularly vulnerable position. The study concludes that due to a lack of formal support for mental health within the region, informal mediums of care are integral to boosting morals, especially among young people.

Surprisingly, even though Australia's COVID-19 cases and death rates were much lower than most countries, coronavirus more severely affected Australian youth compared to other countries, and its influence was felt strongly by Australian teens. An online survey collected responses from 706 Australians aged 12-18 years to analyze the pandemic's impact on adolescent behavior and well-being ( $\mathrm{Li}$ et al. 2021). Three-fourths of participants reported a worsening in mental health since the pandemic began. Australian youth had high levels of insomnia, anxiety, and other forms of psychological distress (Li et al. 2021). Adolescents are particularly vulnerable to mental illness in their developing stage, and the group that administered the study is currently searching for ways to support adolescent emotional health (McLaughlin et al. 2008).

Although Sub-Saharan Africa (SSA) was not as heavily affected by the coronavirus compared to the aforementioned countries, the disease influenced SSA youth's emotional health slightly (Wang et al. 2021). As a response to the growing coronavirus concern, many Sub-Saharan African countries implemented quarantine restrictions. In fact, as of February 2021, SSA governments are recommending schools continue to remain closed and citizens follow all social restrictions to minimize the spread of the disease (Hale 2021). Sub-Saharan Africa reports much fewer COVID-19 cases compared to other nations, which can be attributed to SSA's younger population and quick government action (Roser et al. 2021). Although SSA youth are unlikely to become hospitalized or have severe symptoms when contracting coronavirus, the disease's isolating implications may result in a multitude of emotional and cognitive 
consequences in SSA adolescents (Guan et al. 2020). A survey analyzed COVID-19's impact on young people in three Sub-Saharan countries, Ethiopia, Burkina Faso, and Nigeria. In each of the included countries, the survey collected responses from one rural and one urban location. The survey selected Nouna (rural) and Ouagadougou (urban) in Burkina Faso, Kersa (rural) and Addis Ababa (urban) in Ethiopia, and Ibadan (rural) and Lagos (urban) in Nigeria. The survey acquired data using a phone-based longitudinal survey, which also incorporated a mobile platform and computer-assisted telephone interviewing (CATI). The survey randomly selected 300 households in each rural/urban location. Verbal consent was acquired from parents prior to collecting responses from children under 18. The study interviewed a total of 1,795 adolescents and measured psychological stress levels during the pandemic using a four-item patient questionnaire to formulate a depression and anxiety scale. Each question had a numeric value of $0,1,2$, and 3 , and the total score was calculated by adding up the scores of the four questions, which had a range of 0-12. Most adolescents in Burkina Faso, Nigeria, and Ethiopia did not experience any mental health symptoms during the pandemic (Wang et al. 2021). The median score was 1 for Ouagadougou and Kera and 0 for all other sites. Moderate to severe mental symptoms were present in $4.8 \%$ of adolescents in Kersa and $11.9 \%$ in Nouna. A high anxiety score was present in $10 \%$ of respondents. Severe depression scores were seen in 1\% of Addis Ababa youth and 17\% in Kers (Wang et al. 2021). The survey determined the inadequate amount of data did not sufficiently represent the psychological symptoms of Sub-Saharan African youth during the pandemic, and instead hoped their limited data would push policymakers to address the educational and nutritional needs of adolescents.

\section{Methods}

The open COVID-19 and its Impact on Students data set $(\mathrm{n}=1182)$ was obtained from the online data science collective, Kaggle. The set contains data from a cross-sectional survey conducted in various educational institutions in the Delhi National Capital Region of India. The data encompasses a large range of ages (average and median age $=20 ;$ max-age $=59$, $\min$ age $=7$ ) and includes quantitative, qualitative, and binary data values. Demographic information (age, region) is also included as part of the data. The survey asked participants for the following information: age, region, time spent in online classes, rating of online class experience, medium for online classes, time spent on study, time spent on fitness, time spent on sleep, time spent on social media, preferred social media platform, time spent on TV, number of meals per day, change in weight, health issues during lockdown, ways the students destress, and whether they find themselves more connected with others. This analysis focuses only on 6 variables: weight change, hours of sleep, rating of online class experience, devices used for online learning, favorite activities to destress, and how much time they spent on various things on a day-by-day basis. 
Limited pre-processing was performed due to the high usability of the set. The data was first downloaded as a .csv file and then read into the data analysis platform, Google Sheets. The six categories of interest were isolated after the data were filtered to only include data from respondents $\leq 18$ years of age ( $\mathrm{n}=$ 368). The countif() function was then used to generate graphable data points from the processed data.

The six data points that were graphed were chosen for their relationship to mental health as well as the impact online learning has brought upon the routine lives of students. A conversation about adolescent mental health during the pandemic cannot ignore the realities of online school, and the consequences it had on social and emotional well-being. An irregular sleep schedule and weight gain or loss can be indicative of a mental health issue. Weight fluctuations among students were reported as weight gain, weight loss, or no change (Figure 5). Respondents reported their sleeping habits as an average number of hours slept per night (Figure 6) as $<8$ and $\geq 8$ hours (based on the CDC recommendation that adolescents get at least 8 hours of sleep per night).

The pandemic came hand in hand with online schooling which threw a wrench in the lives of many students. Figure 1 displays the technological device used by students to participate in a virtual schooling environment and shows the number of students who were unprepared or unable to get access to a proper laptop or desktop setup. Additionally, respondents reported their rating of online classes somewhere on a scale from very poor to excellent, and this breakdown is found in figure 4. 
Results

Figure 1

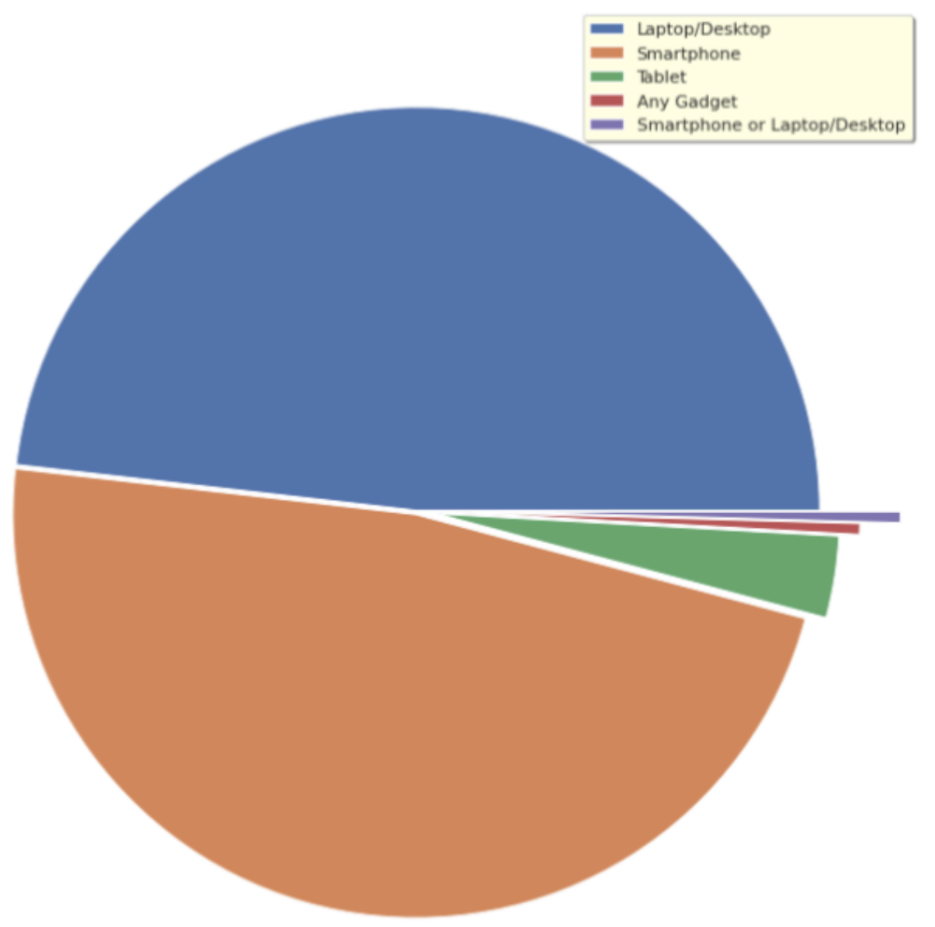

Device Used for Online Learning

Figure 2

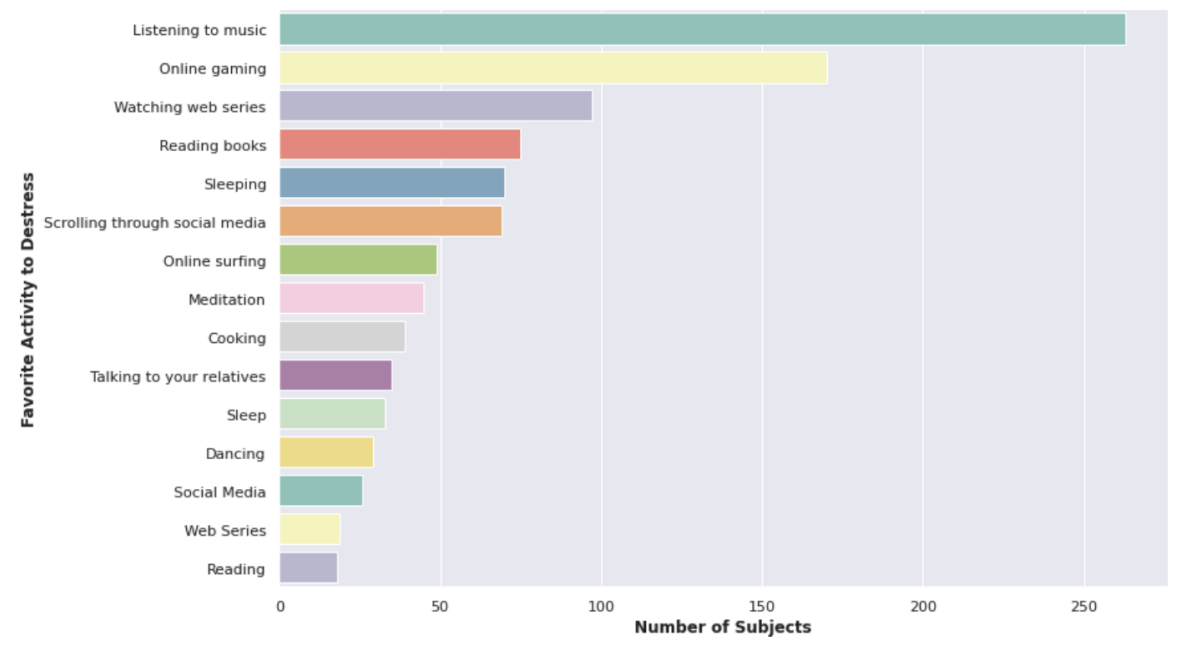


Figure 3

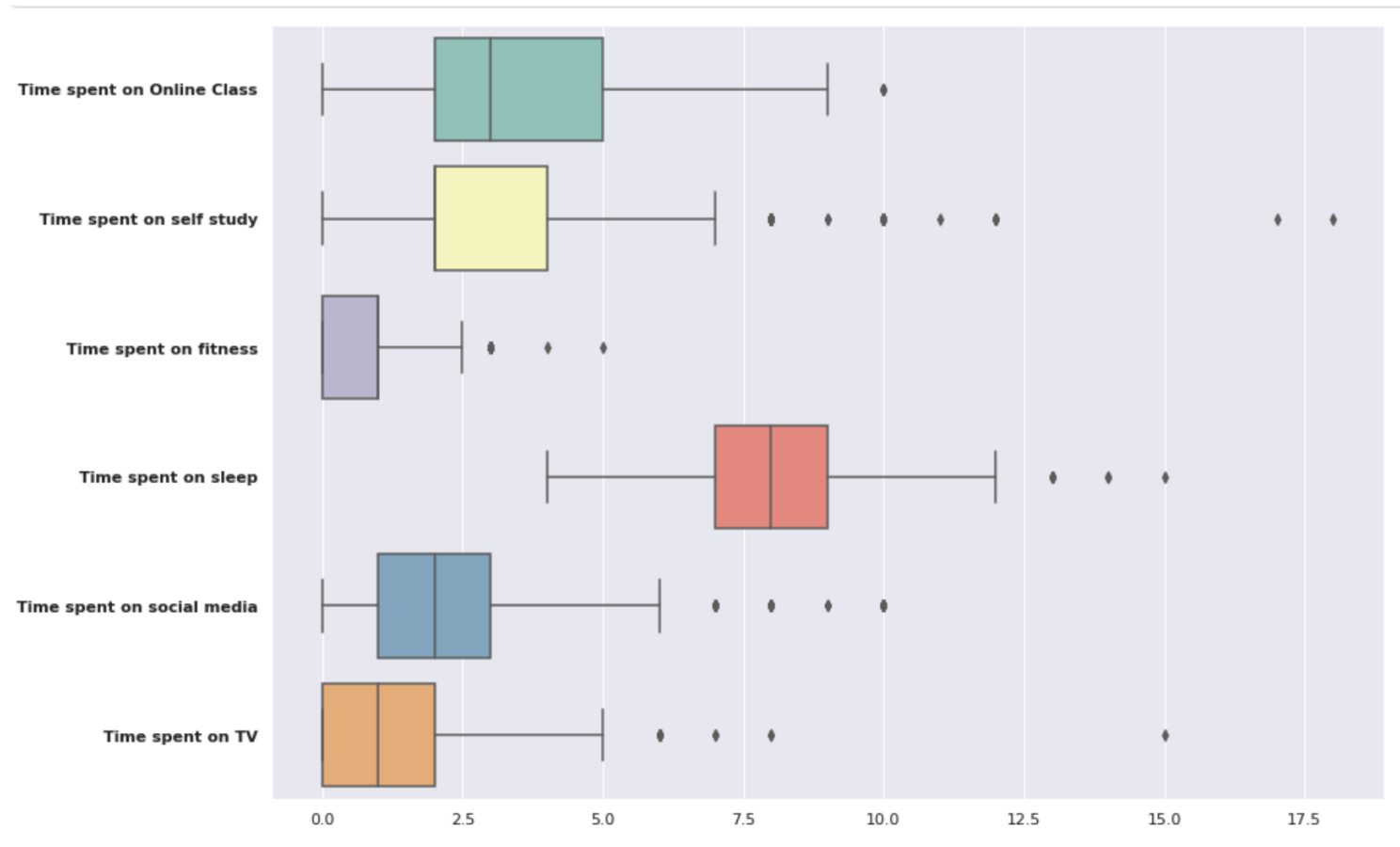

Figure 4

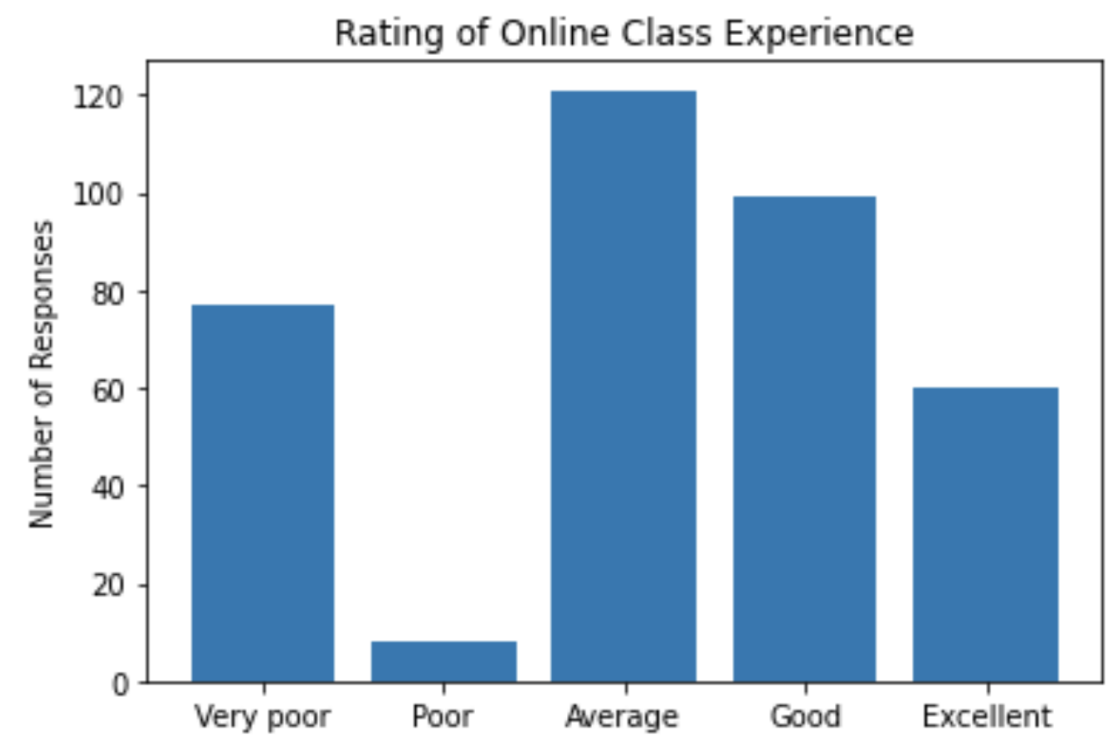


Figure 5

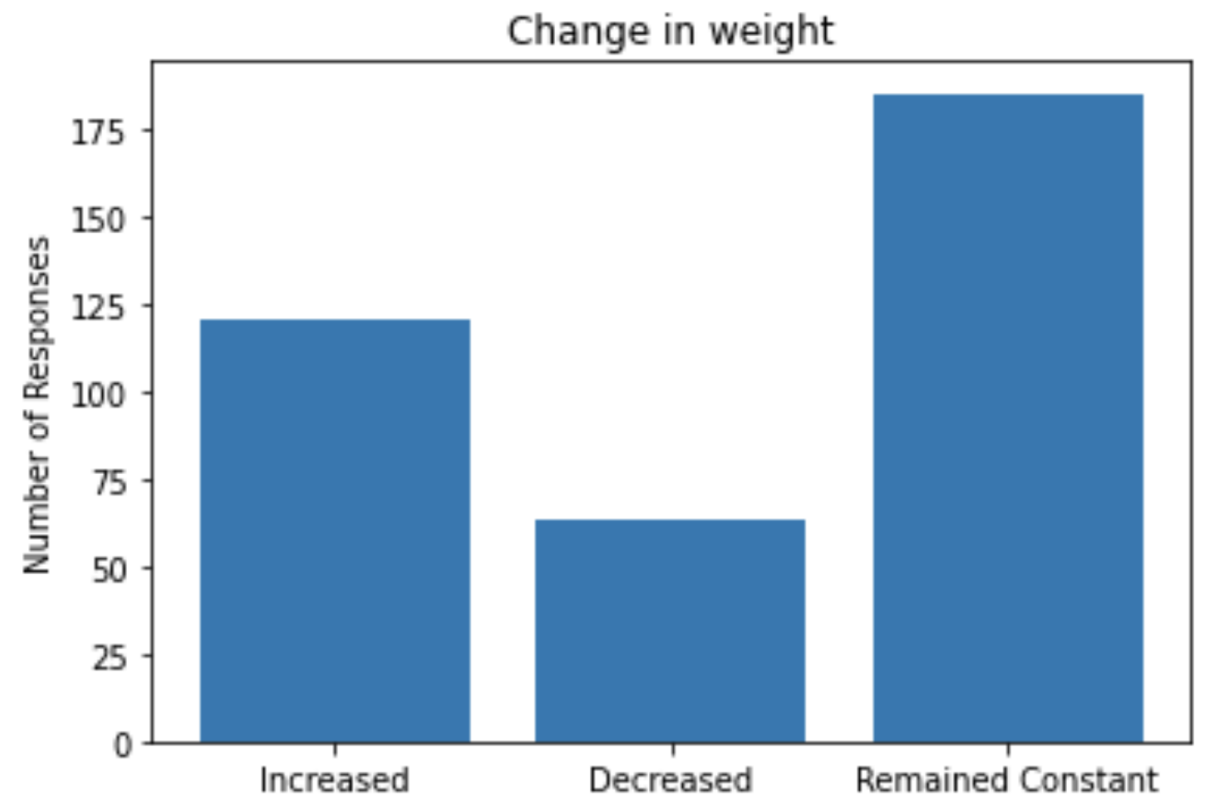

Figure 6

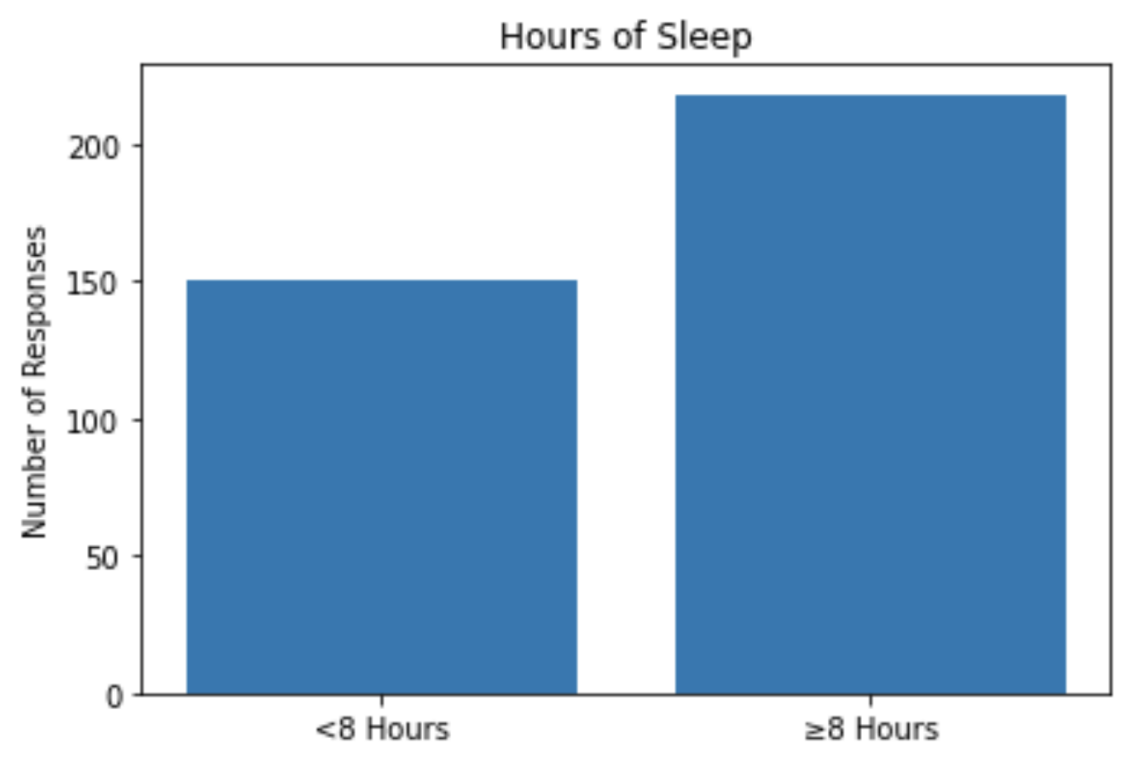




\section{Discussion}

The COVID-19 and its Impact on Students data set $(\mathrm{n}=1182)$ we analyzed consisted of survey data collected from the Delhi Technological University. The Delhi Technological University ran a 2020 survey that analyzed the pandemic's impact on the mental health and daily routines of students living in the Delhi-India region and found similar results (Chaturvedi et al. 2020). The survey asked participants to individually assess the amount of daily time spent on activities during the outbreak, which included school, physical exercise, self-study, and sleep. Respondents also self-evaluated the quality of their use of time, in total collecting responses from 1,182 students. Additional tests were used to analyze correlations between age groups and respondents' psychological states. 20.16 [95\% CI 19.8-20.4] were the participants' mean age, $25.6 \%$ of which were ages 7-17. Students ages 7-17 spent an average of 0.82 h/day [95\% CI 0.76-0.89] exercising, 7.91 h/day [95\% CI 7.77-8.11] sleeping, and 1.68 h/day [95\% CI 1.52 - 1.85] using social media. The vast majority, if not all of the participants, were attending virtual school at the time. Time spent in online classes for students ages 7-17 was significantly higher compared to other age groups (3.69 h/day). 31.5\% of students in this group negatively reviewed their quality of e-learning (2.4\% poor and $29.1 \%$ very poor) (Chaturvedi et al. 2020). A possible reason why e-learning received a considerable amount of negative reviews from Delhi-Indian students is that most teachers were unfamiliar with online tools/technology or were not prepared to teach remotely (Newton, 2020). It's worth considering that prior studies indicate students receiving an online education were more likely to report psychological symptoms than students attending in-person school (Center, K. C. 2021). A longitudinal survey discovered that students attending school virtually during winter in 2020 were more anxious and depressed compared to prior terms (Huckins et al. 2020). Additionally, 51.4\% of responders were not satisfied with their use of time. Further testing revealed emotional and cognitive health declined sharply in participants dissatisfied with their use of time. The Delhi Technological University reasoned that Delhiites, especially students attending school online, were unable to effectively use their time to better their psychological situations during the pandemic. Students could not socialize as easily with friends or perform other typical leisure activities, and often found themselves in isolated, depressive spaces. These spaces worsened mental health in the majority of Delhi-Indian adolescents.

The Delhi- Technological University found, to cope with the pandemic, $26 \%$ of the surveyed students listened to music, $21 \%$ played online games, $9 \%$ read, $9 \%$ used social media, $8 \%$ slept, and $27 \%$ used other methods. $47 \%$ of the surveyed Delhi-Indian students resorted to technology to manage their stress, compared to $45 \%$ of the poll's participants. It can be assumed that many adolescents used the internet as a way of handling stress because COVID-19 ensued quarantine restrictions in most countries that physically 
isolated teenagers from loved ones. Socialization is a key factor for youth development, and the inability to participate in communal activities negatively affects one's mental health. Luckily, modern technology enables teenagers to socialize remotely with friends and family. Many adolescents likely substituted this online form of interaction in place of the physical congregation during the pandemic.

We also analyzed another open-source survey data set (analyses not included in this paper), where participants were all living in the United States and under 18. The poll asked teenagers what factors they believed contributed to their stress. $27 \%$ of participants attributed their stress to strained relationships with their family and friends, $20 \%$ identified teachers as the source of their stress, $13 \%$ attributed it to parents, $9 \%$ to college, $3 \%$ to friends, and $2 \%$ to the lack of educational resources during COVID- $19.20 \%$ of participants were unable to identify the source of their stress. $45 \%$ of these surveyed teenagers mentioned they used technology to manage their stress. We observed other additional ways participants handled their stress, which included speaking with friends (22\%), eating (20\%), exercising (15\%), and drug use (11\%). $17 \%$ of respondents mentioned they had no means of dealing with their stress, and $16 \%$ indicated other methods of addressing stress.

$11 \%$ of the poll's responses mentioned using drugs as a coping mechanism. This piece of data foreshadows that the severity of COVID-19's impact on mental health may result in lifetime consequences. Regular substance use at a young age is often correlated with cognitive and behavioral problems, juvenile delinquency, suicide, illness, and homicide (Bureau of Justice Statistics, 1992). Additionally, in a 2020 Canadian questionnaire, roughly one in five adolescents reported consuming drugs and alcohol at least once a week (Craig, S et al. 2020). This data predicts that COVID-19's impact on mental health may result in lifelong problems for adolescents and their peers. The ever-growing number of teenagers engaged in drug and alcohol use suggests that during their adulthood, a considerable percentage of this generation will face severe psychological and physical consequences as the result of past substance abuse.

The pandemic also imposed a threat to traditional mental health treatments. Most in-person therapy sessions are postponed until further notice. Many health officials now look to telemedicine to support youth mental health. Dr. Karestan Koenen, Professor of Psychiatric Epidemiology at the Harvard T.H. Chan School of Public Health, and Dr. Archana Basu, Research Associate at the Harvard T.H. Chan School of Public Health, and a clinical psychologist at Massachusetts General Hospital, mention health professionals are collaborating globally to create accessible, online resources for mental health. 
We can conclude that COVID-19 harmed children's emotional and cognitive health to a great extent. Our

poll and additional research point out a significant increase in psychological symptoms within adolescents during the pandemic. It can be assumed that quarantine restrictions, school closures, and other constraints suddenly disrupted many young people's daily routines and forced teenagers worldwide to quickly adapt to the new environments COVID-19 imposed. The following economic decline, fear for loved ones, and increase in COVID-19 cases only worsened youth mental health worldwide. Although the seriousness of psychological symptoms felt by young people varied from region to region, our poll and previously mentioned research conclude that COVID-19 led to a decline in emotional and cognitive health in groups ages 10-18. Hopefully, health officials will recognize the mental health crisis at hand and will devise new means to support psychological health in young people. While we are unsure how governments will address the mental health 'pandemic' coronavirus gave rise to, we hope current research, as well as the development of telemedicine and additional policies, serve as an effective response.

\section{Conclusion}

After a conclusive review of data collected from around the world, the impact COVID-19 has had on the psychological health of youth is clear. Our research analyzed data from the United States, Guatemala, India, Canada, Australia, Sub-Saharan Africa, Western Europe, Bangladesh, China, Turkey, and various other regions and nations. We found that adolescents experienced a significant increase in stress levels, anxiety, depression, sleep deprivation, and other mental health-related conditions. These symptoms were often worse among already marginalized groups in society, including people of color, women, and those living in poverty. The cause of these symptoms is attributed to school closure, restrictions on social gatherings and events, separation from friends and family, and the overall stress and anxiety inherent in living through a public health emergency. To cope with heightened mental health issues, our research identified the use of technology such as social media, gaming, and listening to music, as a common way of lowering stress and anxiety levels. A rise in drug use among youth as a means of addressing mental health symptoms was also observed, hinting at the long-term adverse health impacts that could ensue from the pandemic. Although the exact extent of neuro-physical health decline and methods of coping with it varies from region to region, it can be concluded that youth around the world were negatively impacted by the COVID-19 pandemic. Despite growing vaccination rates and a gradual return to normal in some parts of the world, the COVID-19 pandemic will continue to have an immense impact on young people for years to come, even after the virus itself has long faded into the depths of history. 


\section{References}

1. Coronavirus cases: Worldometer. (n.d.). https://www.worldometers.info/coronavirus/.

2. Choukér, A., \& Stahn, A. C. (2020, October 22). Covid-19-the largest isolation study in history: The value of shared learnings from spaceflight analogs. Nature News. https://www.nature.com/articles/s41526-020-00122-8.

3. Singh, S., Roy, D., Sinha, K., Parveen, S., Sharma, G., \& Joshi, G. (2020, November). Impact of covid-19 and Lockdown on Mental Health of Children and Adolescents: A Narrative Review with recommendations. Psychiatry research.

4. Chen, S., Cheng, Z., \& Wu, J. (2020). Risk factors for adolescents' mental health during the COVID-19 pandemic: a comparison between Wuhan and other urban areas in China.

Globalization and health, 16(1), 96. https://doi.org/10.1186/s12992-020-00627-7

5. Mohan BS, Nambiar V (2020) COVID-19: An Insight into SARS-CoV-2 Pandemic Originated at Wuhan City in Hubei Province of China. J Infect Dis Epidemiol 6:146. doi.org/10.23937/2474-3658/1510146

6. Huang Y, Ning Z. Generalized anxiety disorder, depressive symptoms and sleep quality during COVID-19 epidemic in China: A web-based cross-sectional survey. Med Rxiv. 2020. 4. Lima CKT, et al

7. Wang $\mathrm{C}$, et al. Immediate psychological responses and associated factors during the initial stage of the 2019 coronavirus disease (COVID-19) epidemic among the general population in China. International Journal of Environmental Research and Public Health. 2020;17(5):1729

8. Chaturvedi, K., Vishwakarma, D. K., \& Singh, N. (2020, December 25). Covid-19 and its impact on education, social life and mental health of students: A survey. Children and Youth Services Review. https://www.sciencedirect.com/science/article/abs/pii/S019074092032288X?via\%3Dihub\#.

9. Newton, D. (2020, March 26). Most teachers say they are 'not prepared' to teach online. Forbes. https://www.forbes.com/sites/dereknewton/2020/03/26/most-teachers-say-they-are-not-prepared-t o-teach-online/?sh=6e2f85ab7f2c.

10. Center, K. C. (2021, April 20). Mental health effects of online learning. Kentucky Counseling Center. https://kentuckycounselingcenter.com/mental-health-effects-of-online-learning/.

11. Mental Health and Behavior of College Students During the Early Phases of the COVID-19 Pandemic: Longitudinal Smartphone and Ecological Momentary Assessment Study.Huckins JF, daSilva AW, Wang W, Hedlund E, Rogers C, Nepal SK, Wu J, Obuchi M, Murphy EI, Meyer ML, Wagner DD, Holtzheimer PE, Campbell AT J Med Internet Res. 2020 Jun 17; 22(6):e20185. 
12. Banati, P., Jones, N. \& Youssef, S. Intersecting Vulnerabilities: The Impacts of COVID-19 on the Psycho-emotional Lives of Young People in Low- and Middle-Income Countries.Eur J Dev Res 32, 1613-1638 (2020). https://doi.org/10.1057/s41287-020-00325-5

13. Kılınçel, Ş, Kılınçel, O, Muratdağı, G, Aydın, A, Usta, MB. Factors affecting the anxiety levels of adolescents in home-quarantine during COVID-19 pandemic in Turkey. Asia Pac Psychiatry. 2021; 13:e12406. https://doi-org.libproxy.berkeley.edu/10.1111/appy.124

14. American Psychiatric Association . Diagnostic and Statistical Manual of Mental Disorders 5. American Psychiatric Publishing; Arlington, VA, USA: 2013.

15. Atherton, O. E., Ferrer, E., \& Robins, R. W. (2018). The development of externalizing symptoms from late childhood through adolescence: A longitudinal study of Mexican-origin youth. Developmental psychology, 54(6), 1135-1147. https://doi.org/10.1037/dev0000489

16. Bandoli, G., Campbell-Sills, L., Kessler, R. C., Heeringa, S. G., Nock, M. K., Rosellini, A. J., Sampson, N. A., Schoenbaum, M., Ursano, R. J., \& Stein, M. B. (2017). Childhood adversity, adult stress, and the risk of major depression or generalized anxiety disorder in US soldiers: a test of the stress sensitization hypothesis. Psychological medicine, 47(13), 2379-2392. https://doi.org/10.1017/S0033291717001064

17. Beauchaine T.P., Hinshaw S.P. The Oxford Handbook of Externalizing Spectrum Disorders. Oxford University Press; New York, NY, USA: 2015.

18. Breaux, R., Dvorsky, M. R., Marsh, N. P., Green, C. D., Cash, A. R., Shroff, D. M., Buchen, N., Langberg, J. M., \& Becker, S. P. (2021). Prospective impact of COVID-19 on mental health functioning in adolescents with and without ADHD: protective role of emotion regulation abilities. Journal of child psychology and psychiatry, and allied disciplines, 62(9), 1132-1139. https://doi.org/10.1111/jcpp.13382

19. Canino, G., Polanczyk, G., Bauermeister, J. J., Rohde, L. A., \& Frick, P. J. (2010). Does the prevalence of CD and ODD vary across cultures?. Social psychiatry and psychiatric epidemiology, 45(7), 695-704. https://doi.org/10.1007/s00127-010-0242-y

20. CORONA HEALTH APP-Study Studie zur Psychischen Gesundheit Erwachsener Während der COVID-19 Pandemie. [(accessed on 12 February 2021)]; Available online: https://www.rki.de/DE/Content/Institut/OrgEinheiten/Abt2/FG26/CORONA_HEALTH_ APP-Study.html.

21. Cusinato, M., Iannattone, S., Spoto, A., Poli, M., Moretti, C., Gatta, M., \& Miscioscia, M. (2020). Stress, Resilience, and Well-Being in Italian Children and Their Parents during the COVID-19 
Pandemic. International journal of environmental research and public health, 17(22), 8297. https://doi.org/10.3390/ijerph17228297

22. Dong, H., Yang, F., Lu, X., \& Hao, W. (2020). Internet Addiction and Related Psychological Factors Among Children and Adolescents in China During the Coronavirus Disease 2019 (COVID-19) Epidemic. Frontiers in psychiatry, 11, 00751. https://doi.org/10.3389/fpsyt.2020.00751

23. Drechsler, R., Brem, S., Brandeis, D., Grünblatt, E., Berger, G., \& Walitza, S. (2020). ADHD: Current Concepts and Treatments in Children and Adolescents. Neuropediatrics, 51(5), 315-335. https://doi.org/10.1055/s-0040-1701658

24. Gmel, G., Khazaal, Y., Studer, J., Baggio, S., \& Marmet, S. (2019). Development of a short form of the compulsive internet use scale in Switzerland. International journal of methods in psychiatric research, 28(1), e1765. https://doi.org/10.1002/mpr.1765

25. Kessler, R. C., Berglund, P., Demler, O., Jin, R., Merikangas, K. R., \& Walters, E. E. (2005). Lifetime prevalence and age-of-onset distributions of DSM-IV disorders in the National Comorbidity Survey Replication. Archives of general psychiatry, 62(6), 593-602. https://doi.org/10.1001/archpsyc.62.6.593

26. Kessler, R. C., Birnbaum, H., Bromet, E., Hwang, I., Sampson, N., \& Shahly, V. (2010). Age differences in major depression: results from the National Comorbidity Survey Replication (NCS-R). Psychological medicine, 40(2), 225-237. https://doi.org/10.1017/S0033291709990213

27. Kroenke, K., Spitzer, R. L., \& Williams, J. B. (2003). The Patient Health Questionnaire-2: validity of a two-item depression screener. Medical care, 41(11), 1284-1292. https://doi.org/10.1097/01.MLR.0000093487.78664.3C

28. McLaughlin, K. A., Conron, K. J., Koenen, K. C., \& Gilman, S. E. (2010). Childhood adversity, adult stressful life events, and risk of past-year psychiatric disorder: a test of the stress sensitization hypothesis in a population-based sample of adults. Psychological medicine, 40(10), 1647-1658. https://doi.org/10.1017/S0033291709992121

29. Monroe, S. M., \& Harkness, K. L. (2005). Life stress, the "kindling" hypothesis, and the recurrence of depression: considerations from a life stress perspective. Psychological review, 112(2), 417-445. https://doi.org/10.1037/0033-295X.112.2.417

30. Nock, M. K., Kazdin, A. E., Hiripi, E., \& Kessler, R. C. (2007). Lifetime prevalence, correlates, and persistence of oppositional defiant disorder: results from the National Comorbidity Survey Replication. Journal of child psychology and psychiatry, and allied disciplines, 48(7), 703-713. https://doi.org/10.1111/j.1469-7610.2007.01733.x 
31. Racine, N., Korczak, D. J., \& Madigan, S. (2020). Evidence suggests children are being left behind in COVID-19 mental health research. European child \& adolescent psychiatry, 1-2. Advance online publication. https://doi.org/10.1007/s00787-020-01672-8

32. Reardon, T., Spence, S. H., Hesse, J., Shakir, A., \& Creswell, C. (2018). Identifying children with anxiety disorders using brief versions of the Spence Children's Anxiety Scale for children, parents, and teachers. Psychological assessment, 30(10), 1342-1355.

https://doi.org/10.1037/pas0000570

33. Responses to Stress Questionnaire (RSQ) [(accessed on 12 February 2021)]; Available online: https://my.vanderbilt.edu/stressandcoping/rsq/

34. Siste, K., Hanafi, E., Sen, L. T., Christian, H., Adrian, Siswidiani, L. P., Limawan, A. P., Murtani, B. J., \& Suwartono, C. (2020). The Impact of Physical Distancing and Associated Factors Towards Internet Addiction Among Adults in Indonesia During COVID-19 Pandemic: A Nationwide Web-Based Study. Frontiers in psychiatry, 11, 580977. https://doi.org/10.3389/fpsyt.2020.580977

35. Wang, Y., Kala, M. P., \& Jafar, T. H. (2020). Factors associated with psychological distress during the coronavirus disease 2019 (COVID-19) pandemic on the predominantly general population: A systematic review and meta-analysis. PloS one, 15(12), e0244630.

https://doi.org/10.1371/journal.pone.0244630

36. Willcutt E. G. (2012). The prevalence of DSM-IV attention-deficit/hyperactivity disorder: a meta-analytic review. Neurotherapeutics : the journal of the American Society for Experimental NeuroTherapeutics, 9(3), 490-499. https://doi.org/10.1007/s13311-012-0135-8

37. Willoughby M. T. (2003). Developmental course of ADHD symptomatology during the transition from childhood to adolescence: a review with recommendations. Journal of child psychology and psychiatry, and allied disciplines, 44(1), 88-106. https://doi.org/10.1111/1469-7610.t01-1-00104

38. 27. Zhao, N., \& Zhou, G. (2021). COVID-19 Stress and Addictive Social Media Use (SMU): Mediating Role of Active Use and Social Media Flow. Frontiers in psychiatry, 12, 635546. https://doi.org/10.3389/fpsyt.2021.635546

39. Duncan, L., Georgiades, K., Wang, L., Comeau, J., Ferro, M. A., Van Lieshout, R. J., Szatmari, P., Bennett, K., MacMillan, H. L., Lipman, E. L., Janus, M., Kata, A., \& Boyle, M. H. (2019). The 2014 Ontario Child Health Study Emotional Behavioural Scales (OCHS-EBS) Part I: A Checklist for Dimensional Measurement of Selected DSM-5 Disorders. The Canadian Journal of Psychiatry, 64(6), 423-433. https://doi.org/10.1177/0706743718808250

40. Ellis, W. E., Dumas, T. M., \& Forbes, L. M. (2020). Physically isolated but socially connected: Psychological adjustment and stress among adolescents during the initial COVID-19 crisis. 
Canadian Journal of Behavioural Science / Revue canadienne des sciences du comportement, 52(3), 177-187. https://doi.org/10.1037/cbs0000215

41. Fegert, J.M., Vitiello, B., Plener, P.L. et al. Challenges and burden of the Coronavirus 2019 (COVID-19) pandemic for child and adolescent mental health: a narrative review to highlight clinical and research needs in the acute phase and the long return to normality. Child Adolesc Psychiatry Ment Health 14, 20 (2020). https://doi.org/10.1186/s13034-020-00329-3

42. Findlay, L. C., Arim, R., \& Kohen, D. (2020). Understanding the perceived mental health of Canadians during the COVID-19 pandemic. Health Reports, 31(4), 22-27. https://doi.org/10.25318/82-003-x202000400003-eng

43. Galea, S., Merchant, R. M., \& Lurie, N. (2020). The mental health consequences of COVID-19 and physical distancing: The need for prevention and early intervention. JAMA internal medicine, 180(6), 817-818. https://doi.org/10.1001/jamainternmed.2020.1562

44. Hawke, L. D., Barbic, S. P., Voineskos, A., Szatmari, P., Cleverley, K., Hayes, E., Relihan, J., Daley, M., Courtney, D., Cheung, A., Darnay, K., \& Henderson, J. L. (2020). Impacts of COVID-19 on Youth Mental Health, Substance Use, and Well-being: A Rapid Survey of Clinical and Community Samples: Répercussions de la COVID-19 sur la santé mentale, l'utilisation de substances et le bien-être des adolescents : un sondage rapide d'échantillons cliniques et communautaires. Canadian Journal of Psychiatry, 65(10), 701-709.

https://doi.org/10.1177/0706743720940562

45. Perrin, S., Meiser-Stedman, R., \& Smith, P. (2005). The Children's Revised Impact of Event Scale (CRIES): Validity as a screening instrument for PTSD. Behavioral and Cognitive Psychotherapy, 33(4), 487-498. https://doi.org/10.1017/S1352465805002419

46. Schepis, T. S., Desai, R. A., Cavallo, D.A., Smith, A. E., McFetridge, A., Liss, T. B., Potenza, M. N., \& Krishnan-Sarin, S. (2011). Gender differences in adolescent marijuana use and associated psychosocial characteristics. Journal of Addiction Medicine, 5(1), 65-73. https://doi.org/10.1097/ADM.0b013e3181d8dc62

47. Sobell, L. C., Kwan, E., \& Sobell, M. B. (1995). Reliability of a drug history questionnaire (DHQ). Addictive Behaviors, 20(2), 233-241. https://doi.org/10.1016/0306-4603(94)00071-9

48. Zahn-Waxler, C., Shirtcliff, E. A., \& Marceau, K. (2008). Disorders of childhood and adolescence: Gender and psychopathology. Annual Review of Clinical Psychology, 4, 275-303. https://doi.org/10.1146/annurev.clinpsy.3.022806.091358

49. Nirmita Panchal, R. K., \& 2021, M. (2021, May 25). Mental Health and Substance Use Considerations Among Children During the COVID-19 Pandemic. 
https://www.kff.org/coronavirus-covid-19/issue-brief/mental-health-and-substance-use-considerat ions-among-children-during-the-covid-19-pandemic/

50. Fair Health releases study on impact of covid-19 on pediatric mental health: Fair health. FAIR Health Releases Study on Impact of COVID-19 on Pediatric Mental Health | FAIR Health

51. Cary Wu, Yue Qian \& Rima Wilkes (2021) Anti-Asian discrimination and the Asian-white mental health gap during COVID-19, Ethnic and Racial Studies, 44:5, 819-835, DOI:

$\underline{10.1080 / 01419870.2020 .1851739}$

52. Asnaani, A., J. A. Richey, R. Dimaite, D. E. Hinton, and S. G. Hofmann. 2010. "A Cross-Ethnic Comparison of Lifetime Prevalence Rates of Anxiety Disorders." The Journal of Nervous and Mental Disease 198 (8): 551. [Crossref], [PubMed], [Web of Science ${ }^{\circledR}$ ], [Google Scholar]

53. DanMangan. (2021, August 30). Hate crimes against Asian and Black people rise sharply in the U.S., FBI says. https://www.cnbc.com/2021/08/30/fbi-says-hate-crimes-against-asian-and-black-people-rise-in-th e-us.html

54. Dhanani, L. Y., and B. Franz. 2020. "Unexpected Public Health Consequences of the COVID-19 Pandemic: a National Survey Examining Anti-Asian Attitudes in the USA.” International Journal of Public Health 65 (6): 747-754. [Crossref], [PubMed], [Web of Science ${ }^{\circledR}$ ], [Google Scholar]

55. Ong, A. D., C. Cerrada, R. A. Lee, and D. R. Williams. 2017. "Stigma Consciousness, Racial Microaggressions, and Sleep Disturbance among Asian Americans." Asian American Journal of Psychology 8 (1): 72-81.[Crossref], [Web of Science ${ }^{\circledR}$ ], [Google Scholar]

56. Gee, G. C., A. Ro, S. Shariff-Marco, and D. Chae. 2009. "Racial Discrimination and Health among Asian Americans: Evidence, Assessment, and Directions for Future Research." Epidemiologic Reviews 31 (1): 130-151. [Crossref], [PubMed], [Web of Science ${ }^{\circledR}$ ], [Google Scholar]

57. Cheah, C. S., C. Wang, H. Ren, X. Zong, H. S. Cho, and X. Xue. 2020. “COVID-19 Racism and Mental Health in Chinese American Families.” Pediatrics 146, (5): e2020021816. https://doi.org/10.1542/peds.2020-021816. [Crossref], [PubMed], [Web of Science ${ }^{\circledR}$ ], [Google Scholar]

58. Liu, Y., B. K. Finch, S. G. Brenneke, K. Thomas, and P. D. Le. 2020. "Perceived Discrimination and Mental Distress amid the COVID-19 pandemic: Evidence from the understanding America study." American Journal of Preventive Medicine 59 (4): 481-492. [Crossref], [PubMed], [Web of Science ${ }^{\circledR}$ ], [Google Scholar]

59. Goldin, I. \& Muggah, R. (2020). COVID-19 is increasing multiple kinds of inequality. Here's what we can do about it. World Economic Forum. 
https://www.weforum.org/agenda/2020/10/covid-19-is-increasing-multiple-kinds-of-inequality-he re-s-what-we-can-do-about-it/

60. López-Boo, F., Cubides-Mateus, M., Sorio, R., Garibotto, G., \& Berón, C. (2018). Medición de la calidad del entorno familiar de los niños pequeños en Uruguay. Gradientes socioeconómicos en el inventario (Measuring the quality of the family environment of young children in Uruguay.

Socio- economic gradients in the inventory). Inter-American Development Bank

No.IDB-TN-1550

iadb.org/publications/spanish/document/Medici\%C3\%B3n_de_la_calidad_del_entorno_familiar_ de_los_ni\%C3\%B1os_peque $\%$ C3\%B1os_en_Uruguay_Gradientes_

socioecon\%C3\%B3micos_en_el_inventario_HOME_es_es.pdf

61. Acevedo, I., Castro, E., Fernandez R., Flores, I., Perez, M. Alfaro, Szekely, M. \& Zoido, P. (2020). Los costos educativos de la crisis sanitaria en América Latina y el Caribe (The Educational Cost of the Health Crisis in Latin America and the Caribbean). INEEd. Published. https://doi.org/10.18235/0002838

62. UNICEF ( 2020). LACRO Covid-19 Education Response: Update 18 Special Focus on the Provision of Wash Services in Schools. https://www.unicef.org/lac/en/media/17751/file

63. Economic Commission for Latin America and the Caribbean (2020): "Violence against children and adolescents in the time of COVID-19".

www.cepal.org/en/publications/46486-violence-against-children-and-adolescents-time-covid-19.

64. Attanasio, O., \& Rajan, R. (2021). The invisible COVID-19 graveyard: intergenerational losses for the poorest young people and actions to address a human development pandemic. UNDP LAC, C19 PDS No. 26.

blob:https://www.latinamerica.undp.org/9358414c-36fa-40d4-a21d-8978804599da

65. UNICEF LAC. The impact of COVID-19 on the mental health of adolescents and youth. (2020). UNICEF Latin America and Caribbean. https://www.unicef.org/lac/en/impact-covid-19-mental-health-adolescents-and-youth

66. Alonzo, D., Popescu, M., \& Zubaroglu-Ioannides, P. (2021). The current pandemic, a complex emergency mental health impact of the COVID-19 pandemic on highly vulnerable communities in Guatemala. International Journal of Social Psychiatry, 002076402110272. https://doi.org/10.1177/00207640211027212

67. Li SH, Beames JR, Newby JM, Maston K, Christensen H, Werner-Seidler A. The impact of COVID-19 on the lives and mental health of Australian adolescents. Eur Child Adolesc Psychiatry. 2021 Apr 28:1-13. doi: 10.1007/s00787-021-01790-x. Epub ahead of print. PMID: 33913036; PMCID: PMC8080862. 
68. McLaughlin, K. A., \& Hatzenbuehler, M. L. (2008, October 25). Mechanisms linking stressful life events and mental health problems in a prospective, community-based sample of adolescents. Journal of Adolescent Health. https://www.sciencedirect.com/science/article/abs/pii/S1054139X0800298X.

69. Wang, D., Chukwu, A., Millogo, O., Assefa, N., James, C., Young, T., Lankoande, B., Workneh, F., Hemler, E. C., Korte, M. L., Mattei, J., Soura, A. B., Sie, A., Oduola, A., Berhane, Y., \& Fawzi, W. W. (2021, August 11). The COVID-19 pandemic and adolescents' experience in Sub-Saharan Africa: A cross-country study using a telephone survey. AJTMH. https://www.ajtmh.org/view/journals/tpmd/105/2/article-p331.xml.

70. Hale T, Webster S, Petherick A, Phillips T, Kira B, 2020. Oxford COVID-19 Government Response Tracker. Oxford, United Kingdom: Blavatnik School of Government 25.

71. Roser M, Ritchie H, Ortiz-Ospina E, Hasell J, 2021. Statistics and Research: Mortality Risk of COVID-19. Our World in Data. Available at: https://ourworldindata.org/mortality-risk-covid\#case-fatality-rate-of-covid-19-by-age. Accessed February 12, 2021

72. Guan W-j, Ni Z-y, Hu Y, Liang W-h, Ou C-q, He J-x, Liu L, Shan H, Lei C-1, Hui DS, 2020. Clinical characteristics of coronavirus disease 2019 in China. N Engl J Med 382: 1708-1720. Search Google Scholar 